\title{
Teatro Comunitário: um cruzamento sem fronteiras (fenômeno do século XXI)
}

Maria José Lisboa Silva ${ }^{1}$

Recebido em: 15/04/2020

Aprovado em: 11/05/2020

DOI: $10.5965 / 2358092521232020141$

1 Doutora em Estudos de Teatro pela Faculdade de Letras da Universidade de Lisboa (FLUL). Professora no curso de Licenciatura em Teatro na Universidade Federal do Maranhão (UFMA). E-mail: zezelisboa@yahoo.com.br 


\section{RESUMO}

Este artigo aborda três estudos de caso pertinentes às práticas do teatro comunitário estabelecendo conexões além-fronteiras. Objetiva cruzar possíveis informações relacionadas a três grupos teatrais remanescentes, criados a partir da década de 1970, e que desenvolveram uma forma peculiar de sustentabilidade. São eles: Grupo Grita (Brasil); Grupo de Teatro do Centro Cultural Português (Cabo Verde); Grupo de Teatro As Avozinhas (Portugal). Foram averiguados os contributos dessas experiências na perspectiva de incorporar novas abordagens e conceitos para a formação e fortalecimento cívico e artístico das gerações futuras, para que novos grupos de teatro descubram formas criativas e sustentáveis de manter suas produções artístico-culturais aliadas às suas convicções.

Palavras-chave: Teatro comunitário, coletivo teatral, cultura do diálogo.

\section{ABSTRACT}

This article addresses three case studies related to theater practices associated with cross-border connections. It aims to cross possible information related to three remaining theatrical groups, created from the 1970 s and to develop a peculiar form of sustainability. They are: Grita Group (Brazil); Theater Group of the Portuguese Cultural Center (Cape Verde); As Avozinhas Theater Group (Portugal). The following contributions from these perspectives were calculated in order to incorporate new approaches and concepts for the formation and civic and artistic strengthening of future perspectives, for new theater groups to discover creative and sustainable ways of maintaining their cultural artistic productions combined with their convictions. 
Keywords: community theater, theater collective, culture of dialogue.

\section{INTRODUÇÃO}

Visualizo os teatros comunitários do século XXI como teatros "sem telón", iluminados pela luz do sol e em caso de escuridão pela unificadora claridade das velas; com abertura ao infinito e como meio para fortalecer a vida das pessoas, sem nenhum tipo de exclusão, dotando a existência de uma dimensão poética. (ADAME, 2017, p. 50)

Este artigo aborda três estudos de caso pertinentes às práticas artísticas do teatro comunitário, fenômeno crescente do século XXI, na tentativa de trazer para o bojo do debate as demandas que advêm desse processo, nos quais estão inseridos os grupos criados a partir da década de 1970, localizados em diferentes continentes e separados pelo Oceano Atlântico, nomeadamente o Grupo de Teatro do Centro Cultural Português - GTCCPM (Mindelo/Cabo Verde); o Grupo de Teatro As Avozinhas (Palmela/Portugal) e o Grupo Grita (Maranhão/Brasil).

Para tanto, vamos convocar para o centro do debate o autor Domingo Adame (2017), com o seu olhar planetário é categórico ao afirmar que o cosmo, em geral, tem sido bombardeado por imensas mudanças, nas quais a nossa espécie tem sofrido profundas desigualdades sociais. Ainda afirma o autor, referindo-se às I e II Guerras Mundiais, como o prenúncio da autodestruição global sem, contudo, mencionar as outras guerras que geram profundas sequelas.

Convida-nos Adame (2017), a partir de uma reflexão de outros autores, como Edgar Morin (2003), a valorizar e dar mais sentido ao nosso presente, afirmando-o como uma necessária transformação da atual sociedade e um crescimento espiritual que atenda a uma justiça planetária. Este tipo de crescimento, sendo visivelmente marcado por "[...] visões sectárias, excluden- 
tes e autoritárias [...]" (ADAME, 2017, p. 28), que provoca, de certa forma, um "[...] isolamento cognitivo e vivencial dos indivíduos para consigo mesmos, com a natureza e com a comunidade, bem como à ruptura de sua criatividade e a sua expressividade [...]" (Idem), dos sujeitos nele implicados.

O autor prossegue a sua exposição abordando seis dimensões do Teatro Comunitário do século XXI. Dentre elas, destaco a Dimensão Transpolítica, com base na "antropolítica" nos termos de Morin (2003 apud ADAME, 2017, p. 42) "[...] o que quer dizer uma política do humano, que teria como missão mais urgente a de solidarizar o mundo, começando com as solidariedades locais $[. . .]^{\prime \prime}$.

Seria uma forma de suplantar as adversidades advindas principalmente do individualismo que geram consequentemente barreiras, sobretudo, de compreensão e comunicação no seio das comunidades. Implantar uma nova convivência social, que Adame (2017) se utiliza da expressão "cosmodernidade" que difere do comportamento homogêneo da sociedade moderna, estimulado pelo agenciamento das mídias, em especial a televisão.

Adame (2017) avança na perspectiva de elucidar as possibilidades desta nova convivência,

[...] é necessário, ao mesmo tempo, preservar e abrir as culturas, e se situar entre o local e o planetário. É preciso fomentar a ética da diversidade e da compreensão, quer dizer, viver a ética em uma troca dialógica entre egocentrismo e altruísmo, mas, principalmente, como um ato de religação com o próximo, com a comunidade, com a sociedade e com a espécie humana. Uma auto-ética constituída pela ética de tolerância, de liberdade, de fidelidade para com a amizade e o amor. A ética da compreensão é uma ética comunitária que procura entender e transformar a incompreensão, causa de violências e de guerras, é também uma ética de esperança e de resistência para a crueldade humana (ADAME, 2017, p. 42).

Assim, ele nos instiga a considerarmo-nos "[...] cidadãos planetários [...]" (ADAME, 2017, p. 29), com uma condição prioritária: todos os que fazem teatro comunitário serão pioneiros 
dessa cidadania, em que assuntos comuns pertinentes a cada sociedade serão de interesse coletivo, como uma rede solidária, no qual um será responsável pelo outro, consequentemente, responsável pela nação e seus desdobramentos, ou seja, haverá uma nação sem fronteiras.

Com esta nova forma de sentir o planeta e, esta dimensão poética do teatro comunitário no século XXI para o reencantamento do mundo, é que vislumbramos as histórias descritas até aqui, como realidades sem fronteiras.

Desta forma, coube-nos fazer um recorte a partir de uma pesquisa in loco em três países (Brasil, Cabo Verde e Portugal), resultante do doutoramento em Estudos Artísticos, na Universidade de Lisboa, Portugal, dos grupos: Teatro do Centro Cultural Português de Mindelo - GTCCPM (1993), de Mindelo (Cabo Verde); Grupo de Teatro As Avozinhas (2002), de Palmela (Portugal) e Grupo Grita (1975), de São Luís do Maranhão (Brasil), que possibilitam um olhar sobre o teatro comunitário transversalizado por experiências distintas, cada uma com suas particularidades, buscando um diálogo entre as culturas, suas semelhanças e diferenças na prática teatral.

\section{GRUPO GRITA (SÃO LUÍS-MARANHÃO/BRASIL)}

No sentido de preencher uma das lacunas no registro de experiências, especialmente, do teatro maranhense que, embora tenha um acervo gigantesco de histórias para contar, ainda permanece obscura a sua origem, que começa no século XIX, quando os portugueses e suas companhias aportavam na capital de São Luís com suas grandes produções teatrais; contudo, o que se apresenta para nós é apenas uma publicação que resgata em parte esta história desta época, do autor José Jansen (1974), Teatro no Maranhão: até o fim do século XIX e, mais recentemente, do ator, diretor e autor Aldo Leite (2007), Memória do Teatro Maranhense, entre outros estudos sistemáticos de origem mais individual, monografias, dissertações e artigos.

Neste contexto convoca-se para o centro da discussão, e fa- 
zer, sobre o farto acervo e ainda disperso material, um trabalho de reflexão sobre o Grupo Grita e o teatro comunitário. Carvalho (2002 apud SILVA, 2002, p. 12) assina o prefácio do meu livro e assinala o Grupo Grita como,

A 'fábrica de sonhos' fica no bairro Anjo da Guarda - lugar onde sonhar tornou-se uma necessidade básica. De lá têm saído grandes atores. Atores esses que aprenderam com o teatro a arte de transformar os problemas diários num recado que a sociedade precisaria reler todos os dias.

O Grupo Grita compôs o objeto da pesquisa por: a) situar-se na América Latina; b) por ser, talvez, um dos grupos mais antigos do Brasil com este perfil comunitário; c) pela sua localização geográfica que no âmbito nacional, o Maranhão pertence ao Nordeste; portanto, longe do circuito cultural/tradicional e de grandes referências mundiais, como os eixos (Rio de Janeiro e São Paulo) e; d) segundo Silva (2002), pelo trabalho que desenvolve agregando centenas de pessoas de diferentes classes sociais e localidades em uma montagem teatral, num processo colaborativo.

\section{GRUPO DE TEATRO AS AVOZINHAS (PALMELA/ PORTUGAL)}

Seguindo os critérios de seleção e pela facilidade geográfica de acesso, era necessário selecionar um grupo de teatro singular e de cariz comunitário que fosse da Europa, precisamente de Portugal. Optou-se pelo Grupo As Avozinhas em virtude da sua longa experiência em teatro comunitário, aliado à característica peculiar de formação, em termos de gênero e de proposta cênica: é composto por mulheres, todas avós com mais de 60 anos e com pouca formação escolar. A pesquisadora pode experienciar o processo criativo do grupo, o que lhe deu acesso para realização de entrevistas com seus membros.

Um grupo que carrega a tradição de ser transgressor, sub- 
versivo e contemporâneo², como pode ser isto? Como podem estar à frente de algumas gerações da década de 1980-1990? Como tais mulheres-avós resistem à repressão, preconceitos e dificuldades advindas da sociedade, muitas das vezes, dos seus próprios filhos, netos e maridos? Indagava-me.

Fruto de seu contexto histórico, o Teatro das Avozinhas passa pelo 25 de abril de 1974 - uma história de ditadura e libertação na chamada Revolução dos Cravos - bem como, metaforicamente, aproxima-se das personagens Três Marias, presentes na obra As Novas Cartas Portuguesas (Barreno; Horta; Costa, 1972) que foi um divisor de águas no que se refere à conquista da emancipação da mulher.

As Avozinhas testemunham a ação repressiva da ditadura militar, as quais através da insurgência feminina driblaram os infortúnios da desigualdade social de gênero e garantiram seu lugar na sociedade. Os desígnios femininos se limitavam à procriação e à manutenção da família, seus desejos eram proibidos, seu corpo e sexualidade eram reprimidos. A liberdade feminina era condenada, passível de punição e condenação, pois socialmente a mulher era aceita como ser inferior e subjugada ao homem.

\section{GRUPO DE TEATRO DO CENTRO CULTURAL PORTUGUÊS DE MINDELO - GTCCPM (SÃO VICENTE-MINDELO/ÁFRICA)}

Para estabelecer conexões além-fronteiras, fundamentar o papel do teatro no contexto social e comunitário, agregar novas abordagens e conceitos no âmbito da democratização cultural e explorar as possibilidades do teatro enquanto instrumento de transformação social, incorporou-se o GTCCPM na pesquisa.

A proximidade com o GTCCPM começou virtualmente, com

2 Os trabalhos abordam temas de luta das mulheres pela garantia de igualdade de direitos, como no espetáculo O Auto da feiticeira Cotovia (2007), de Natalia Correia. 
uma longa pesquisa online, visitando alguns sites de grupos de teatro, sobretudo da África, pois buscava um outro continente como via motora para ampliar o foco da pesquisa em tela, mas que pertencesse, sobretudo, à Comunidade dos Países de Língua Portuguesa (CPLP). Entretanto, destaca-se no trabalho deste grupo a crioulização cênica (BRANCO, 2016), a qual se refere traduções/adaptações, no sentido de apropriação dos clássicos da dramaturgia universal em crioulo ${ }^{3}$.

Observa-se que a língua cumpre o papel de aproximar as culturas clássicas às culturas locais/regionais. O ponto de partida das produções dos espetáculos do GTCCPM passa, sobretudo, pela sua comunidade, pela necessidade do seu público. Podemos identificar essa essência, por exemplo, na montagem intitulada A Casa de Nha Bernarda, baseada no texto de A Casa de Bernarda Alba (1936), de Garcia Lorca, uma passagem radical de uma obra tradicionalmente clássica, séria, introspectiva, para uma obra com raiz bem popular, cômica, divertida, sem perder, contudo, a essência do drama e nem o contexto político, à maneira das peças aristofanescas.

\section{METODOLOGIA DA INVESTIGAÇÃO}

Trata-se de uma pesquisa de natureza aplicada, com finalidade exploratória e descritiva, a fim de compreender as variáveis intersubjetivas do campo social que está sendo abordado. Quanto aos procedimentos, utilizou-se pesquisa bibliográfica e de campo, por meio de recuperação de fontes bibliográficas de autores que abordam a temática, tais como: Eugène van Erven (2001); Nogueira (2015); Barreno, Horta, \& Costa (1972); Silva (2002); Baumam (2003), Adame (2017), entre outros. Aliada à

3 Um dialeto específico da região, que tem o português como língua oficial. Embora exista tradução das dramaturgias, o encenador acredita que o uso na língua nativa aproxima a realidade do texto ao contexto social, cultural e política vigente, haja vista que o crioulo é a língua da comunidade, do cotidiano. Considerada popularmente como língua nacional pois é a mais utilizada nas situações informais (BRANCO, 2016). 
fontes primárias e secundárias de dados, observação participante e realização de entrevistas com coordenadores e membros dos grupos estudados (PRODANOV; FREITAS, 2013).

Acerca da coleta de dados, por meio da observação participante e aplicação de entrevistas, optou-se por um recorte temporal longitudinal em virtude da participação em eventos e troca de experiências com os três grupos. Correspondente ao Grupo de Teatro do Centro Cultural Português (Mindelo/Cabo Verde) fundado em 1993, a pesquisa de campo deu-se, por ocasião da realização do $23^{\circ}$ Festival Internacional de Teatro MINDELACT, que ocorreu em Mindelo, com entrevistas individuais e recolhas de materiais.

Quanto ao Grupo de Teatro As Avozinhas, a pesquisa foi realizada em diferentes momentos: participação como intérprete em uma performance do grupo, bem como por ocasião do $20^{\circ}$ Festival de Artes de Rua (FIAR), em Palmela (Portugal). Por fim, com o Grupo Grita (São Luís/Brasil) foram coletados dados durante a $37^{a}$ realização do projeto da Via Sacra e por entrevistas online, com o uso do software Skype.

\section{O CRUZAMENTO DOS TRÊS ESTUDOS DE CASO: O GTCCP, O GRUPO GRITA E O TEA- TRO AS AVOZINHAS}

Para fins de análise transversal dos dados, o cruzamento foi feito utilizando o método de Análise de Conteúdo proposto por Bardin (2011), que organiza, seleciona e categoriza a informação de modo a torná-la passível de análise. Com isso, organizou-se em torno de quatro eixos centrais: a) o sentido de grupo; b) a composição de grupo/coletivo; c) os grupos e o encontro com a comunidade e d) perspectivas de manutenção de um grupo/ coletivo teatral; os quais serão abordados nas subseções desta seção.

Com base em uma experiência acumulada, o GTCCP, o Grupo Grita e o Grupo de Teatro As Avozinhas dialogam e se alimentam diretamente de novas abordagens da cena teatral, fonte de 
inspiração que faz emergir trabalhos considerados inusitados e, consequentemente, as conquistas de visibilidade e reconhecimento. Apesar destes grupos surgirem em décadas diferentes, advirem de origem popular, oriundos do desejo de uma comunidade, compostos por diferentes gerações, há uma preocupação com os conteúdos abordados e com a estética das montagens.

Utiliza-se neste trabalho a categoria de atores/atrizes comunitários, para evidenciar que não há uma formação técnica, a princípio, mas que ao longo da caminhada se aperfeiçoam sob orientação de sua direção, tal qual a característica do teatro comunitário citada por Erven (2001, p. 22-23) “[...] ora de artistas profissionais de fora - que podem ou não, terem sido ativos em outros tipos de teatro profissional - ora por artistas amadores locais".

Nomeio esta terminologia "atores/atrizes comunitários" para fins de compreensão que os envolvidos possuem outras ocupações profissionais. Contudo, a orientação por parte de profissionais possibilita-os construírem personagens e desenvolverem técnicas de atuação e encenação, seja pelas técnicas e exercícios propostos pelo diretor, a trilha composta por músicos, a sonoplastia e iluminação executadas por respectivos profissionais, dentre outras funções desenvolvidas por quem possua expertise na área.

\section{O SENTIDO DE GRUPO}

A concepção de grupo parte do princípio de que os trabaIhos são desenvolvidos em equipe, nos quais todos contribuem à sua maneira, com direitos e deveres a serem exercidos na construção de uma identidade comum. As contribuições perpassam desde as ideias à força do trabalho para execução dos projetos coletivamente, para que fortaleçam as relações sociais e alcancem resultados comuns.

Esta prática de grupo se difere e muito do que se pensa atualmente com a globalização que, por sua vez, transforma o mundo e transforma as pessoas. Segundo Bárbara Santos (2017), vive-se em uma sociedade do monólogo, na qual não 
há escuta, impossibilitando o pleno exercício do diálogo e da comunicação. Consequentemente, não se estabelecem as relações sociais, convergindo com o pensamento de Adame (2017) da necessidade da cultura do diálogo para o século XXI.

Bauman (2003) aponta a globalização como um dos principais fatores responsáveis pela desarticulação social, construindo o que ele chama de um estado de putrefação da sociedade, em que o lixo humano ${ }^{4}$ está cada vez mais amontoado nos arredores da cidade. Consoante, Adame (2017) alerta da necessidade de restabelecer as relações humanitárias, elencando o teatro comunitário como uma das possíveis vias para o reencantamento do mundo.

Corroborando, o teatro comunitário está presente em várias partes do mundo, "[...] estes estão evoluindo no Sudeste Asiático insular, na Europa provincial, na costa metropolitana do sul da Califórnia, na costa da América Central, na África do leste rural ou na Austrália suburbana." (ERVEN, 2001, p. 3). A unidade de ação de um grupo é fundamental para descortinar e fazer desabrochar novos caminhos, mesmo que seja "[...] um paraíso perdido ou um paraíso ainda esperado [...]" (BAUMAN, 2003, p. 9). Ainda assim, há quem acredite ser possível recuperar este paraíso, em um lugar seguro e aconchegante no meio de tantas dificuldades, como assinala Peruzzo e Volpato (2009).

\section{A COMPOSIÇÃO DE GRUPO/COLETIVO}

De acordo com sua prática, o GTCCP se considera mais um coletivo de produção do que um coletivo de teatro, em virtude da ausência de um elenco fixo. A cada produção o elenco é renovado, formado, principalmente, pelos alunos (jovens e adultos) egressos do curso de formação de atores promovido pelo Cen-

\footnotetext{
4 Para o autor, compreende-se por lixo humano o excedente populacional gerado pela urbanização especulativa das cidades, oriundo da estrutura do sistema de produção e reprodução capitalista, que determina os direitos sociais a partir do poder financeiro dos indivíduos. Assim como o excedente de trabalhadores desempregados. (BAUMAN, 2003).
} 
tro Cultural Português (CCP). Cabe distinção que um coletivo de teatro não necessariamente é sinônimo de grupo de teatro - um não substitui o outro, sobretudo a convivência em grupo, mas segundo Veloso (2008, p. 03), eles nos convidam

[...] a explorar outros modos de estar junto. Seu modo de formatação é por meio de serviços. Escolhem um foco de interesse, ou um tema agregador de grupos e artistas "avulsos" e num tempo pré-estabelecido desenvolvem o trabalho. O Coletivo sobrevive o tempo que dura a empreitada.

A composição se dá somente em tempos de montagem, o que caracteriza, por vezes, para os adeptos de grupos fixos (núcleo artístico estável) a sua não existência (VELOSO, 2008), o que Branco (2017), fundador do GTCCP, corrobora, uma vez que optou em manter um coletivo. Efêmero, mas com uma convivência grupal significativa.

Em relação aos outros dois grupos faz-se jus à nomeação, considerando grupo como algo duradouro, estável, fixo, embora dinâmico na sua estrutura organizacional e artística, com abertura para inclusão de outros atores/atrizes comunitários ou até mesmo de profissionais nas diferentes áreas artísticas. Para fins de contributos na melhoria do trabalho, seja plástico ou interpretativo, os quais os três grupos utilizam deste mecanismo de prática e de experimento coletivo, numa perspectiva de uma produção conjunta, ora uma criação coletiva, ora um processo colaborativo.

\section{OS GRUPOS E O ENCONTRO COM A COMU- NIDADE}

A vivência com os grupos comunitários ocorrem em três grandes eventos: o FIAR (Palmela/Portugal), o Festival MINDELACT, (Mindelo-Cabo Verde/África) e o Projeto da Via Sacra do Anjo da Guarda, (São Luís-Maranhão/Brasil), entre outros encontros pontuais desenvolvidos pelos grupos, As Avozinhas, GTCCP de Mindelo e o Grupo Grita, respectivamente. 
Estes projetos agregam em seu entorno variáveis comuns, como as dezenas de participantes voluntários na organização dos eventos por meio da economia de afetos, conceito estabelecido por João Branco (2016, p. 164), enquanto "[...] um pacto social e cultural na perspectiva de uma troca de conhecimentos, aprendizagens e oportunidades".

Destaca-se a mobilização de centenas de pessoas oriundas de várias localidades, assim como as características de promoção no desenvolvimento socioeconômico cultural, provocando, entre outros: a) o aquecimento na economia local; b) a qualificação profissional nas diferentes áreas; c) a valorização dos artistas e artífices - anônimos e famosos - partícipes dessa construção histórica, e; d) além de ser um espaço de formação do público, agregando a este contexto o valor turístico do evento.

Outra característica similar é a questão da sustentabilidade financeira desses projetos. É comum, ano após ano, os festivais enfrentarem dificuldades para realização, embora sejam ações já consolidadas e conhecidas pelos setores públicos e privados e valorizada pela comunidade local e até internacional, haja vista a extensa participação de estrangeiros. Ainda assim, há um descaso no tocante à investimento financeiro, mesmo após várias edições demonstrarem um potencial retorno de investimento para o Estado, há sempre um recomeço sem garantias (uma incógnita de parceria desses órgãos).

No entanto, apesar de uma aparente fragilidade destes projetos pela falta de definição financeira, há um forte componente agregado que faz diferença: o envolvimento de centenas de comunitários nos trabalhos voluntários, cujo sentimento de pertencimento é imponente: É meu, é teu, é nosso. Amplia-se o entendimento de comunidade para além de um paraíso perdido ou esperado, mas enquanto potência presente que ressurge com força total, com a glocalização ${ }^{5}$, na qual "[...] revitaliza-se o apreço pelo local, pela comunidade, pelo familiar [...]" (PERUZZO; VOLPATO, 2009, p. 139) sem, contudo, negar as vantagens e desvantagens da quebra de fronteiras à produção do lixo humano, respectivamente (BAUMAN, 2003).

5 Neologismo resultante das palavras "globalização" e "localização". 
Este estado de aparente inércia e complexidade das ações que regem as relações locais e comunitárias, se mobilizam e se articulam no sentido de unir as duas frentes, global e local, criando e recriando identidades próprias que garantam o avanço e a estabilidade social, principalmente, nestes "[...] tempos implacáveis que vivemos, tempos de competição e de desprezo pelos mais fracos [...]" (BAUMAN, 2003, p. 8) e ainda "[...] Evoca a sensação de solidariedade, vida em comum: é a segurança em meio à hostilidade [...]" (PERUZZO; VOLPATO, 2009, p. 140).

Caracteriza-se a valorização das raízes locais, o apego à nossa cultura - uma prática recorrente dos repertórios teatrais desses grupos em estudo, ao evocar textos de autores nacionais, sejam dramáticos ou não dramáticos, que exaltam a nossa história. Bem como adaptação de obras de tradição popular, lendas e ladainhas, com cortes, recortes e costuras, que circunscrevem as produções teatrais com um olhar para a nossa terra, para a nossa gente e para o nosso chão - a nossa comunidade - "[...] uma arena, um lugar de articulação e de confronto de ideias [...] onde as pessoas adquirem suas experiências mais fundamentais e substanciais da vida social, fora dos limites do lar." (COHEN, 1985 apud NOGUEIRA, 2015, p. 11), o que configura ser uma comunidade - uma entidade em constante diálogo.

Deste modo, se estabelece a cultura do diálogo porque o teatro comunitário se constitui do todo (o geográfico e o social), de maneira que os compromissos políticos e artísticos são fundamentais para o alcance dos objetivos, produzindo unidade e, ao mesmo tempo, diversidade cultural, conforme adianta (Lola) Dolores de Matos $^{6}$ em entrevista a Fradique (2016):

O nosso objectivo é sempre criar um objecto artístico de diálogo entre mundos diferenciados. [...] O FIAR implica um encontro com a comunidade, com a aproximação dos públicos, com as áreas contemporâneas. Também da integração do artista na comunidade. [...]. Hoje em dia são transversais às artes contem-

6 Dolores de Matos (1957-2019) era atriz, encenadora e produtora. Criou, na década de 1990, o Grupo de Teatro As Avozinhas e desde 1999 foi diretora do FIAR Centro de Artes de Rua, em Palmela/PT. 
porâneas, as relações com as comunidades, o sentido para a comunidade etc. [...]. (FRADIQUE, 2016, p. 81).

O encontro com a comunidade propiciado pela participação no FIAR representou, subjetivamente, a experiência com a poesia e a música das ruas, o teatro presente no vigilante noturno, ou como o malabarismo solitário de uma monociclista. Experienciar a dança, o circo e o teatro de uma "(in)certaidade"7. Transitando neste universo poético, sob sol escaldante pelas ruas, ruelas, becos, ladeiras e casas antigas. Descendo e subindo escadarias, que mais uma vez o FIAR comemorou os seus 20 anos a "fiar" o lugar, com a licença do trocadilho: um lugar de fios que se cruzam e entrecruzam com a arte da cena.

\section{PERSPECTIVAS DE MANUTENÇÃO DE UM GRUPO/COLETIVO TEATRAL}

O contexto no qual estão inseridos os grupos supracitados e a problemática do qual se sustentou a pesquisa em tela, permitiu-nos conjecturar que as perspectivas estavam alicerçadas em quatro pilares: a) a formação teatral; b) a produção teatral; c) o experimentalismo, e; d) a cultura do diálogo, abordados a seguir.

\section{A FORMAÇÃO TEATRAL}

Uma ação para renovação. Um estratagema de fomento das artes teatrais que de forma sistemática agrega uma formação integral de preparação do ator, no sentido da interpretação, técnica vocal, expressão corporal, dança, canto etc., englobando também treinos de competências técnicas como design de luz e som, construção de cenários e figurinos, na perspectiva de qualificar os membros dos grupos aventados.

7 Espetáculo do Grupo de Teatro As Avozinhas no evento do FIAR, em Palmela/ Portugal. 
Esta iniciativa permite uma renovação do quadro em todos os sentidos, numa eterna troca de conhecimento e experiência que vão potencializar as gerações futuras e, através do estudo, da pesquisa e do espírito inovador, poder-se-ão propor novas concepções artísticas e metodológicas, para fins da exequibilidade dos trabalhos e motivação dos agentes facilitadores, seja coletivo teatral ou grupo de teatro.

Esta ação compreende também, numa outra tangente, a formação de novos agrupamentos de teatro, (uma realidade constatada no contexto do Grupo Grita e o GTCCPM), e o último, talvez o mais importante - a formação de um público mais exigente, perspicaz, que critica, mas aplaude e estimula novas produções.

\section{A PRODUÇÃO TEATRAL}

Uma ação de convivência, em que a troca de experiência e o exercício do fazer teatral contribuem para o amadurecimento e o fortalecimento do grupo; em que o que está em pauta é a cultura do diálogo, que num gesto solidário cruza as informações, ampliando o seu repertório discursivo com outras narrativas e cria no outro uma expectativa curiosa para mais uma aprendizagem. Portanto, uma produção teatral contínua vai proporcionar uma melhor aproximação e estímulo entre o elenco e, assim, contornar-se-ão eventuais embaraços. A produção teatral "[...] é arte congregadora de múltiplas disciplinas técnicas e artísticas [...]" (BRANCO, 2003, p. 25) e por que não dizer também, disciplinas multidisciplinares das áreas humanas?

\section{O EXPERIMENTALISMO}

Uma ação provocadora. É uma forte componente dos três grupos pelo fato de não estarem presos a nenhum tipo de repertório que provoque a repetição e o desgaste. É necessário surpreender sempre o público e a si próprio, com novas perspectivas de abordagens, com novas linguagens e novos textos. 
Seja um coletivo de produção, como é o caso do GTCCPM, sempre com um elenco renovado na sua maioria, mas, acima de tudo, a renovação de multiplicadores, através do curso de formação. Seja como grupo de teatro, como é o caso do Grupo Grita e o Grupo de Teatro As Avozinhas. Sendo que o Grupo Grita, além da formação teatral, consta em seu planejamento, a cada dois anos, durante a eleição de uma nova diretoria, como ponto de pauta a inclusão e exclusão de membros efetivos, depois de uma avaliação. Desta forma, renovar-se-á o quadro de efetivos do grupo, garantindo sua manutenção, o que justifica os 45 anos de fundação.

Quanto ao Teatro As Avozinhas, como proposta firmada entre as integrantes, esta renovação não acontecerá, segundo a diretora artística e fundadora do grupo, o que se pode antever diante desta determinação é uma morte antecipada do grupo, haja vista que o espetáculo continuará, enquanto houver uma só avozinha, depois disto, desaparecerá, ficando somente o seu legado.

Assim, nesta busca constante desses novos caminhos e desafios, estes grupos se afirmam como protagonistas neste cenário universal, criando e recriando formas, adaptando textos, sobretudo os de cariz nacional e original (textos próprios) que potencializam a cultura local e que apontam para novas concepções dramatúrgicas, artísticas e estéticas.

\section{A CULTURA DO DIÁLOGO}

Esta é uma componente que precisa estar infinitamente presente para o sucesso de seres humanos e de organizações. É um pressuposto básico do saber falar, mas sobretudo, do saber ouvir, tão distante hoje em dia com a sociedade do monólogo (SANTOS, 2017). É um exercício de todos os dias de respeito e cidadania e os três estudos de caso, acredito, terem demonstrado esse processo - dialogar para superar. Talvez seja por isso que Branco (GTCCPM) opte por um 'coletivo de produção' e um 'coletivo teatral'. "Não sei trabalhar de outro jeito [...]" (BRANCO, 2017, informação verbal), diz ele, em um tom de desabafo, mas 
cultiva a cultura do diálogo.

Observou-se, na vivência com os grupos, aspectos enfrentados pela cultura do diálogo, tais como: a) relações sociais e conflitos de convivência; b) enfrentamentos de socialização para efetivação dos processos criativos, em virtude de divergências de opinião; c) exercício da coletividade na tomada de decisões; d) questões pessoais dos envolvidos que interferem no trabalho coletivo, dentre outras.

Assim, apresenta-se o teatro comunitário, sobretudo nas comunidades rurais e periféricas, como instrumento de potencialização de lideranças, não somente no campo artístico, mas comunitário e político, construindo bases e vínculos de fortalecimento cívico e artístico para gerações futuras da comunidade. Nota-se a necessidade de equilibrar as demandas internas dos grupos com as demandas externas das comunidades, para que os sujeitos compreendam o mundo e suas dificuldades de forma positiva, enxergando e construindo possibilidades concretas para o reencantamento do mundo, aos moldes do proposto por Adame (2017).

\section{CONSIDERAÇÕES FINAIS}

Formulamos as considerações finais, nos quais se apresentam, parcialmente, os resultados da pesquisa de doutorado, os quais incidiram na importância das práticas do teatro de cariz comunitária - frente única de uma rede solidária, concebida para servir uma comunidade, que reverbera como sendo um movimento intercontinental.

Será que poderíamos dizer que o teatro comunitário é um passaporte que vem unir a todos nós? Talvez, porque se ampliam novas possibilidades de intervenção do teatro comunitário e de audiências, de modo a ser uma arte sem estigmas, sem preconceitos - uma arte integrativa sem, contudo, perder seus traços identitários, que se unem a todo este contexto, através da forma de organização estrutural, com capacidade de autodesenvolvimento e de gerenciamento autônomo, participativo e democrático. 
Estes grupos deixam-nos uma lição, a de que é necessário criar um discurso próprio e que este esteja em diálogo permanentemente com a voz e o corpo da comunidade, potencializando em cada ação e em cada montagem aqueles sujeitos sociais e teatrais, na perspectiva de estarem sempre descobrindo o novo - um novo homem, uma nova mulher, um novo lugar, e que a tão famosa/desejada simbiose entre sujeitos artísticos e comunitários aconteça.

Quase poderíamos invocar como metáfora aquilo que é apanágio de uma arte muito antiga e que o Brasil e Portugal cultivam de igual modo há séculos. De rendas é agora o discurso que testemunha um tecimento apoiado em bilros, de cujos cruzamentos se vai fiando um todo. Entrecruzando os fios do fiar brotam dos bilros as formas que um desenho conjunto fará perdurar. É na beleza e delicadeza da renda, na solidez de cada ponto individual e na trama de todos os ligamentos que encontramos a imagem que corresponde ao nosso sincero desejo de que um cruzamento sem fim possa garantir longa vida a todos e a todas, apoiados no que fizeram, como ainda fazem e como ainda hão de fazer muito mais, por si, por nós, por todos, o Grupo Grita, o Grupo de Teatro do Centro Cultural do Mindelo e o Grupo de Teatro As Avozinhas.

E, por fim, sem esgotar o debate que estes grupos nos propõem a discutir, tudo o que envolve uma vivência coletiva, como até a própria nomenclatura que fundamenta a sua diversidade como teatro concebido especificamente para servir uma comunidade. É com esta pluralidade de interesses, valores e princípios, que diretamente nos dizem respeito e em nome da qual somos convocados a agir e a reagir, que sentimos o reencantamento de sermos parte e todo ao mesmo tempo, como bem nos ensinou Márcia Pompeo ${ }^{8}$ - Nossa Pioneira! Nossa grande Mestra! Uma reverência nunca é demais!

8 Professora do Centro de Artes (CEART) da Universidade do Estado de Santa Catarina (UDESC), falecida em agosto de 2019. Desenvolveu inúmeros estudos e pesquisas na área do teatro comunitário. 


\section{REFERÊNCIAS}

ADAME, D. Teatro comunitário do século XXI para o reencantamento do mundo. In: Hugo Cruz, Isabel Bezelga, \& Paulo Rodrigues Simões (ed.). Práticas Artísticas Comunitárias. Lisboa: Fundação Calouste Gulbenkian/PELE, 2017, p. 27-50.

BARDIN, Laurence. Análise de Conteúdo. São Paulo: Edições 70, 2011.

BARRENO, M. I., HORTA, M. T. COSTA, M. V. da. Novas Cartas Portuguesas. Porto/Lisboa: Dom Quixote, 1972.

BAUMAN, Z. Comunidade. Em busca de segurança no mundo atual (Trad. Plínio Dentzien). Rio de Janeiro: Jorge Zahar, 2003.

BRANCO, J. Não se Ouve Nada Além do Pranto, texto inserido no programa da peça. In: J. Branco (coord.). Dez Anos de Teatro. São Paulo: Centro Cultural Português, 2003, p. 139-141.

BRANCO, J. Crioulização Cênica: em Busca de uma Identidade para o Teatro Cabo-verdiano. 2016. Tese (Doutorado em Comunicação, Cultura e Artes). Universidade do Algarve, Faculdade de Ciências Humanas e Sociais.

NOGUEIRA, M. P. Teatro e Comunidades: A experiência Brasileira. In: CRUZ, Hugo (coord.). Arte e Comunidade. Lisboa: Fundação Calouste Gulbenkian/PELE e Dgartes, 2015, p. 11-26.

ERVEN, E. V. Community theatre: Global Perspectives. London and New York: Routledge, 2001.

FRADIQUE, T. A atracção dramatúrgica pelo real: etnografias do actor-não-actor. 2016. Tese (Doutorado em Antropologia) Faculdade de Ciências Sociais e Humanas, Universidade Nova de Lisboa, Lisboa. Disponível em: http://hdl.handle. net/10362/29481. Acesso em: 22 jan. 2018. 
JANSEN, José. Teatro no Maranhão: até o fim do século XIX. Rio de janeiro: Olímpica, 1974.

LEITE, Aldo de Jesus Muniz. Memória do teatro maranhense. São Luís: EdFUNC, 2007.

MORIN, Edgar. El método V: La humanidad de la humanidad. Madrid: Catedra, 2003.

PERUZZO, C. M. K. \& VOLPATO, M. de O. Conceito de comunidade, local e região: inter-relações e diferenças. Revista Líbero, São Paulo, v., 12, n. 24, p. 139-152, dez. de 2009.

PRODANOV, Cleber Cristiano. FREITAS, Ernani Cesar de. Metodologia do Trabalho científico: métodos e técnicas de pesquisa e do trabalho acadêmico. 2. ed. Novo Hamburgo: Feevale, 2013.

SANTOS, Bárbara. Teatro do Oprimido e educação: entrevista com Bárbara Santos. Disponível em: https://www.youtube.com/ watch?v=HKAAy33tYP4, 2017. Acesso em: 12 maio 2020.

SILVA, M. J. L. GRUPO GRITA: sua estética e sua política (Grupo de Teatro do Maranhão). Concurso literário e artístico "Cidade de São Luís/2001". São Luís: Lithograf, 2002.

VELOSO, Verônica Gonçalves. Grupo ou Coletivo - uma questão de tempo. In: Associação Brasileira de Pesquisas e Pós-graduação em Artes Cênicas. v. 9, n. 1. Anais eletrônicos [...] São Paulo: USP, 2008. Disponível em: https://www.publionline.iar.unicamp. br/index.php/abrace/article/view/1435/1548. Acesso em: 12 maio 2020. 